\title{
The Effectiveness of Environmental Impact Assessment for Nuclear Power Plant
}

\author{
Eko Susanto* \\ Center for Nuclear Technology, Material and Radiomentry Indonesian Nuclear Energy Agency \\ *Coresponding author: zuza_its@yahoo.com
}

Received May 27, 2013; Revised June 20, 2013; Accepted July 29, 2013

\begin{abstract}
Environmental assessment has been an important consideration for the nuclear industry since the creation of the International Atomic Energy Agency. The environment, in the broadest sense, encompasses man and his world, comprising both animate and inanimate components. The physical environment includes surface geography, geology, soils, climate, surface water, and groundwater. The biological environment comprises all living organisms, including plants and animals. In examining the environment through various trophic levels, impacts on human health are ultimately considered. Environmental impact assessment (EIA) is a process in which environmental factors are integrated into project planning and decision making. An environmental impact assessment is comprised of an examination of the local environment around a proposed project, an examination of the proposed project, and a prediction of the potential impacts of the project on the physical, biological and socioeconomic environment, with the objective to judge the acceptability of the project and control those impacts to acceptable levels, while maintaining the viability of the project. This paper examines the effectiveness of environmental impact assessment process for nuclear facilities that includes EIA itself, human induced events, defence in depth, Corporate Social Responsibility and acceptance by the public in the development plan of nuclear power plants in Indonesia. The study of the effectiveness environmental impact assessment using flow chart and the environmental priority system in some indicators are expected to minimize the negative impacts that may occur.
\end{abstract}

Keywords: effectiveness, environmental impact, nuclear energy

Cite This Article: Susanto, Eko, "The Effectiveness of Environmental Impact Assessment for Nuclear Power Plant.” Applied Ecology and Environmental Sciences 1, no. 4 (2013), 61-66. doi: 10.12691/aees-1-4-5.

\section{Introduction}

Over the last few decades, the development of science and technology, economic growth and the remarkable shift of industrial structure has occurred. However, the negative aspect of this growth is several global issues, such as population explosion, increasing demand for energy, climate change and global warming [1]. Finding solutions to global problems is an important factor in ensuring sustainable development and highly needed [2]. Nuclear Power emit almost no greenhouse gases, and therefore seen by many as part of the solution to the problem of global warming and climate change. Entry into force of the Kyoto Protocol and carbon trading schemes provide a real financial benefit to avoiding greenhouse gases. This increases electrical energy atraktivity generated by a low level of carbon as nuclear power and renewable energy. Indonesia plans to build a nuclear power plant which could have significantly impact on the environment, health, and social impacts. Environmentally development implies to improve the welfare and quality of life in order to keep supporting sustainable development. This means that the execution of an activity shall be followed by efforts to prevent and control pollution and or destruction of the environment [3]. The development in technology and industry, as well as the increasing use of radioactive substances in various fields of science, led to the necessity of thinking of the environmental management plan as well. Environmental management problems need to be handled carefully to maintain, prevent and improve the quality of the environment. The environmental impact of the construction are partially planned and partially unplanned which can be positive and negative [4]. The construction and operation of a nuclear power or research reactors and supporting laboratories need to be investigated to reduce, minimize or eliminate the effects that may occur. Effect of radioactive substances to the environment need to be monitored by measuring radioactivity in the environment. Analysis of radioactivity in the environment is part of the environmental impact analysis. From the data obtained can be determined whether or not the possibility of contamination of radioactive substances into the environment. In order to achieve the desired quality of life, man seeks at all costs to process and utilize the existing natural resources. Utilization of natural resources should pay attention to the power of environmental carrying capacity. Reduced carrying capacity of nature decreased nature's ability to support a human life. Having an environmental impact assessment system in place that prevents negative impact on the ecosystem is the key to effective ecosystem conservation. Environmental impact assessments are the only chance for citizens to be publicly informed or express their opinions for projects expected to impact the environment. 
The priority of environmental conservation measures, or mitigation hierarchy, is especially important. Three levels of mitigation are avoidance, minimization, and compensation. Adverse environmental impacts which can be avoided are avoided, even by cancelling the project. Unavoidable impacts are then minimized to the extent possible, with the remaining impact compensated for as a final measure.

Establishing power plants to generate electricity is necessary for people to have comfortable life. No matter how necessary those development projects, the negative impact on the environment must be considered and the design stage of a project justified in relation to environmental considerations. It is therefore very important in the design stage of a project to take into account not only social and economic aspects, but also environmental protection considerations. This paper examines the effectiveness of the environmental impact assessment of nuclear facilities in Indonesia. The focus in this paper includes the study of environmental impact assessment, human induced events, Corporate Social Responsibility (CSR) and community acceptance in the development plan of nuclear power plants in Indonesia.

\section{Materials and Methods}

The effectiveness of environmental impact assessment has been studied using flow chart. The priority system of environmental impact assessment in a number of indicators should be analyzed in the preparation of environmental impact assesment. Study of the impact on the physical and chemical component, biology, public health and socio-cultural activities performed on each component in order to obtain data and critical analysis of major impact.The environmental priority system in some indicators are expected to minimize the negative impacts that may occur.

\section{Result and Discussions}

\subsection{Environmental Impact Assessment Study}

The concept of sustainable development is intended to synchronize the third main aspects of development, namely economic, socio-cultural and environmental aspects. The idea is to have the intent that the economic, social, cultural and environmental impacts must be related to one another, so that the elements of an interconnected unity should not be separated and pitted against each other. Environmental assessment has been an important consideration for the nuclear industry since the founding of the International Atomic Energy Agency in 1957. The last 20 years have seen rapid growth in environmental legislation in accordance with the increased requirements for environmental assessment. Environmental assessment process is still evolving today. Integrated impact assessment has been established as a central element in the evaluation of impacts and response options. Integrated impact assessment techniques attempt to integrate knowledge from different disciplines, such as atmospheric science, hydrology, agriculture and economics. By understanding the dynamics and changes every event that happens in a place or region, is used to determine the sensitivity, vulnerability or limit the possibility of changes in the environment. Assessment can be used to raise awareness of climate change and the potential impacts of the uncertainty that will be incurred with the construction planning of nuclear power plants. Reducing the greenhouse effect due to increased greenhouse effect has become a major countries concern and decision makers. Nuclear power plants can be an alternative choice because it does not result greenhouse gas emissions [4]. Studies related to comparative assessment of environmental and health impacts of nuclear installations have also been carried out. This study covers the stages of normal operation and at the time of the accident. Nuclear installation is free from air pollution to climate change. Nuclear instalation is not emit greenhouse gases $\mathrm{SO}_{2}$, $\mathrm{NOx}, \mathrm{CO}_{2}$, and $\mathrm{CH}_{4}$ [5].

An effort should be made to minimize the negative impacts of any activity or business obligations imposed in the preparation of the feasibility study of the preparation of documents such as Environmental Impact Assessment (EIA). Study of the impact on the physical component clams, biology, public health and social culture must be performed on each component of activity in order to obtain the data and critical analysis of the impact that will have to be managed. Flow chart at every stage of activities can be seen below. The process of determining major and significant impact at every stage of the phase praconstruction, construction, operation and post-operation. The environment includes the physical aspects of chemical, biological and socio-cultural with respect to the other activities around the nuclear plant project and the advice and opinions of the community. A literature review, content analysis (consulting citizens, mass media) and professional judment should be done in determining the method of identifying major and significant impact (hypothetical). The physical environment includes the surface of the geography, geology, soils, climate, surface water, and groundwater. Biological environment consisting of all living organisms, including plants and animals (both vertebrates and invertebrates). Environmental problems, impacts on human health are things to consider. In many countries, environmental (often called the socio-economic) social and economic included in the environmental assessment. Economic, social and cultural issues is extremely important when a nuclear power plant will be developed in an indigenous area is very different with the area from people who are interested in developing nuclear power plants. Environmental impact assessment is a process in which environmental factors are integrated into project planning and decision making. Environmental impact assessment consists of examination of the local environment surrounding the proposed project, examination of the proposed project, and the prediction of potential environmental impacts of the project on physical, biological and socio-economic development, with the aim of receiving a project decision-making and control impacts to a level that can be accepted.

By analyzing nuclear installations identified potential adverse impacts of the project, the quality of impact assessments, and to the extent that public concerns have been incorporated into the decision-making. An example is how a nuclear EIA to evaluate the potential public health impact due to radiation releases, which is a standard component environmental impact assessment in most countries. In the United States, for example, EIA 
statements include calculations [of the] estimates of the maximum [radiation] dose that would be received by individuals living near the facility and the collective dose that would be received by the total population potentially affected [6]. EIA will be used as supporting data project, a preparation documents that must be met before the installation is built. Preparation of EIA can also be done by an environmental consultant who regularly preparing EIA related nuclear installations. However, it should be noted that these consultants have to know for sure about the nuclear power plant. Background radioactivity, radioactivity levels at the time of operation and postoperation predicted such a way that is safe for humans and the environment. The basic thing that should really be considered is the responsibility to determine the main effects of the release of radioactive material into the environment. Monitoring of environmental radioactivity around the site before, during and after the operation should be performed regularly. Air-quality monitoring of the chimney and around the site, and wastewater effluent should be monitored regularly. The study of the effectiveness of environmental impact assessment has also been carried out. The three main components are the focus of the study is the EIA study itself, community consultation and expert opinion. The study was conducted by analyzing a number of nuclear projects that have received permission, whether all process actually identified associated potential adverse impacts of the project, the quality of the impact assessment, and the extent to which public opinion has been a consideration in the decision making [6].
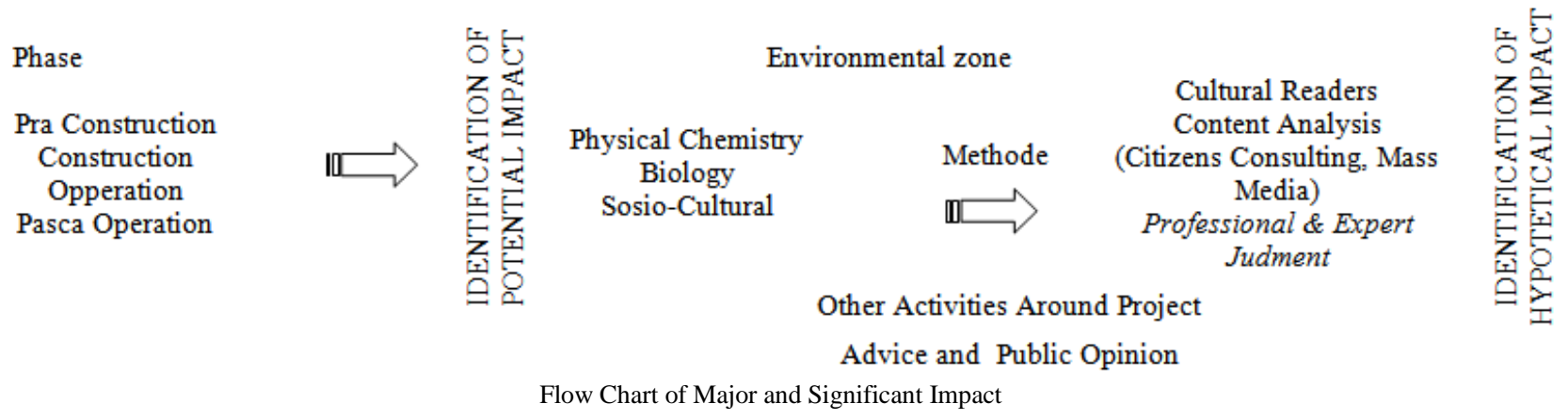

Table 1. Priority system and environmental assessment of each indicator

\begin{tabular}{|c|c|c|}
\hline Indicator & Environmental Priorities & Environmental Impact Assessment \\
\hline \multirow[t]{2}{*}{ Geology } & \multirow{2}{*}{$\begin{array}{l}\text { Description of the geology and topography necessary for the } \\
\text { prevention and preservation } \\
\text { Affected area and measures }\end{array}$} & Loss prevention and use of surficial soil or fertile soil \\
\hline & & $\begin{array}{l}\text { Estimation and measures due to soil loss and sedimentation } \\
\text { Conservation of excessively slant area }\end{array}$ \\
\hline \multirow{4}{*}{$\begin{array}{l}\text { Flora, } \\
\text { fauna }\end{array}$} & \multirow{4}{*}{$\begin{array}{l}\text { Identification of species distribution, species diversity, and } \\
\text { designation of conservation sites }\end{array}$} & Change estimation and measures of flora and fauna \\
\hline & & $\begin{array}{l}\text { Consideration of breeding season, habitat of migrant birds and so } \\
\text { on }\end{array}$ \\
\hline & & Effects and estimation due to habitat destruction of flora and fauna \\
\hline & & $\begin{array}{l}\text { Measures of natural vegetation conservation and share of green } \\
\text { zone }\end{array}$ \\
\hline Hydrology & $\begin{array}{l}\text { Status of water resource use and water supply plan } \\
\text { Effect and measure of quantity on river network }\end{array}$ & $\begin{array}{l}\text { Effects and measures of river bed and watershed } \\
\text { Estimation and measures of rive maintenance flow }\end{array}$ \\
\hline Land use & \multicolumn{2}{|l|}{ Analysis and evaluation of site selection considering near land use } \\
\hline Radiology & Environmental radioactivity & $\begin{array}{l}\text { Radiological Baground } \\
\text { Estimation of radioactivity in the reactor site } \\
\text { Estimated release radioactivity into the environment } \\
\text { Measurement of exposure to workers and the public }\end{array}$ \\
\hline Air quality & $\begin{array}{l}\text { Investigation for sufficient distance from the project site to the } \\
\text { impact area, and formation of buffer zone } \\
\text { Identification the relationship between wind velocity and pollutant } \\
\text { dispersion }\end{array}$ & $\begin{array}{l}\text { Identification emission source } \\
\text { Comparison of emission source and emission rate with national } \\
\text { ambient levels } \\
\text { Identification of mitigation Measures } \\
\text { Review of fuel plan and heat supply process }\end{array}$ \\
\hline \multirow[t]{2}{*}{ Water } & $\begin{array}{l}\text { Analysis of relationship between water supply plan and water } \\
\text { consumption }\end{array}$ & $\begin{array}{l}\text { Analysis and measures of determining to meet the total water } \\
\text { pollution load management standard }\end{array}$ \\
\hline & $\begin{array}{l}\text { Analysis of relationship between water supply plan and water } \\
\text { consumption } \\
\text { Analysis and measures of determining to meet the total water } \\
\text { pollution load management standard }\end{array}$ & $\begin{array}{l}\text { Estimation of water quality and measure of water quality } \\
\text { conservation } \\
\text { Mitigation measures of non-point source pollution } \\
\text { Measure of leachate treatment } \\
\text { Conservation measures of ground water quality and quantity }\end{array}$ \\
\hline $\begin{array}{l}\text { Noise, } \\
\text { vibration }\end{array}$ & $\begin{array}{l}\text { Estimation and measures of mobile source (traffic, airplane and so } \\
\text { on) noise levels }\end{array}$ & $\begin{array}{l}\text { Identification and measures of } \\
\text { Noise source } \\
\text { Estimation and mitigation measures of noise and vibration due to } \\
\text { explosive use and so on } \\
\text { Layout plan on fixed source pollution (Factory, facilities and so } \\
\text { on) }\end{array}$ \\
\hline Landscape & $\begin{array}{l}\text { Use of the existing landscape and making plan considering the } \\
\text { characteristics of land use }\end{array}$ & $\begin{array}{l}\text { Quantitative review and measures of effects due to change in main } \\
\text { view points }\end{array}$ \\
\hline
\end{tabular}


Over the last 30 years, Environmental Impact Assessment (EIA) in Korea has played an important role in decision-making processes particularly for environmentally sensitive projects. Evaluation of environmental impact assessment to predict the possible environmental impacts and designing mitigation measures appropriate [7]. Shown in Table 1, the priority system of environmental impact assessment in a number of indicators that should be analyzed in the preparation of environmental impact. In addition to the indicators listed in the table influences socio-cultural aspects should also be considered

\subsection{Human Induced Events}

Human Induced Events or incidents caused by human activity is a human activity that can change the geosphere, biosphere and landscapes that promote and / or the triggering of certain hazards and increase environmental hazards. Types of human activity has the potential to endanger the existence of a nuclear plant because it can potentially release toxic chemicals and gases, explosive, fire, such as industrial activities (chemicals, oil and gas, electricity, etc.), Mining, roads, railways, aviation , ports, gas pipelines, airports,seaports and military activities [8]. Evaluation of site characteristics affect the safety of the installation, the design of nuclear installations is evaluated based on safety standards, taking into account the characteristics of the location, the risks associated with external hazards, and the potential impact on the environment that may arise. Appropriate measures should be taken to ensure that the overall risk is still acceptable and as small as possible. Consideration of potential impacts to nearby hazards related to the use of land around the plant. Non-radiological impacts are also occured around the site of the nuclear facility, because the use of chemicals, thermal release, the potential for explosions and deployment of chemical products must be taken into account in the evaluation of site selection. The potential interaction between effluent nuclear and non-nuclear, such as the combination of heat or chemicals with radioactive material in liquid effluents, should be considered. Evaluation of the hazards associated with natural events and human-induced should also be a consideration. Examination related to the frequency and severity of natural disasters should be done because it affects the safety and security of the installation. Radiological characteristics of the environment in the area that may be affected by potential radiological impacts in operational states and accident conditions should be investigated. To measure the magnitude of the potential impact of contamination on the environment, the assessment of releases that occur in normal and abnormal conditions should be available. Population growth projected around the site is also be investigated. Potential radiological impacts in operational states and accident conditions of the people in the region, including the effects that can lead to emergency measures, should be evaluated taking into account relevant factors, including the distribution of population in the vicinity [9]. As one of the important aspects in the IAEA Safety Standard NS-G-3.1 (2002), human induced events can otherwise provide a threat to nuclear facilities and activities in the area of installation nuklir [10]. Potential sources of external events caused by human activity include: (a) Sources of equipment (Stationary Sources), (b) Source moves (Mobile Sources). Human activities should be monitored during the life of the nuclear installation to ensure the consistency of the design assumptions were made, so one of the important safety factors into consideration, including the safety and external events caused by human activity (External Human Induced event). All human activities both from fixed and mobile activities are then determined by screening a safe distance (Screning Distance Value / SDV) in accordance with the IAEA guide.

\subsection{Defence in Depth}

The lessons learned from the accident at Three Mile Island, timely feedback of operating experience helped to strengthen each level of defence in depth, and to identify weaknesses in the design, construction, operation and testing of equipment, as well as in the related analysesThe Chernobyl accident in the Ukrainian Republic of the Union of Soviet Socialist Republics in 1986 demonstrated the possible consequences of inadequate defence in depth and the importance of organizational issues such as the need for an effective regulatory regime and for a safety culture. It also focused attention on medium and long term contamination due to radioactive releases and the role of off-site emergency planning. An assessment of the effectiveness of defence in depth has become an important means of assessing general plant safety.

Table 2. Level of Defence in Depth [11]

\begin{tabular}{|l|l|l|}
\hline $\begin{array}{l}\text { Levels of defence } \\
\text { in depth }\end{array}$ & Objective & Essential means \\
\hline Level 1 & Prevention of abnormal operation and failures & $\begin{array}{l}\text { Conservative design and high quality in } \\
\text { construction and operation }\end{array}$ \\
\hline Level 2 & Control of abnormal operation and detection of failures & $\begin{array}{l}\text { Control, limiting and protection systems } \\
\text { and other surveillance features }\end{array}$ \\
\hline Levels 3 & Control of accidents within the design basis & $\begin{array}{l}\text { Engineered safety features and accident } \\
\text { procedures }\end{array}$ \\
\hline Level 4 & $\begin{array}{l}\text { Control of severe plant conditions, including prevention of accident } \\
\text { progression and mitigation of the consequences of severe accidents }\end{array}$ & $\begin{array}{l}\text { Complementary measures and accident } \\
\text { management }\end{array}$ \\
\hline Level 5 & $\begin{array}{l}\text { Mitigation of radiological consequences of significant releases of } \\
\text { radioactive materials }\end{array}$ & Off-site emergency response \\
\hline
\end{tabular}

Defence in depth consists in a hierarchical deployment of different levels of equipment and procedures in order to maintain the effectiveness of physical barriers placed between radioactive materials and workers, the public or the environment, in normal operation, anticipated operational occurrences and, for some barriers, in accidents at the plant. Defence in depth is implemented through design and operation to provide a graded protection against a wide variety of transients, incidents and accidents, including equipment failures and human errors within the plant and events initiated outside the plant. The general objective of defence in depth is to 
ensure that a single failure, whether equipment failure or human failure, at one level of defence, and even combinations of failures at more than one level of defence, would not propagate to jeopardize defence in depth at subsequent levels [11].

\subsection{Corporate Social Responsibility}

Utilization of a nuclear power plant may impact of human life, both effects are positive or a negative impact. The positive impact is expected to enhance the quality and comfort of human life, but the impact is not expected to be negative because it can reduce the quality and comfort of human life. Environmental management and monitoring should be done to overcome the negative effects that may occur. The owner of nuclear power plants need to participate in CSR as a form of awareness of entrepreneurs to society. The concept of a link between the interests of economic, social, cultural and environmental known as CSR. CSR is the integration between business and value, the value at which the interests of stakeholders, customers, employees, investors and the environment is reflected in the policies and actions of the company. CSR is a voluntary action aimed at closer company with real issues in the community that can offer companies a solution that should be done. CSR forms such as work environment is good management, corporate partnerships with local communities through a variety of activities that are empowering to help improve the welfare of local communities. Relating to the environment, CSR can be started from the company that includes the handling and management of industrial waste does not pollute the environment. The concept of CSR requires companies not only develop a profit for himself but also take responsibility for the improvement of quality and the surrounding community. CSR is also not just a charity committed to the community, but more on community development [4].

\subsection{Public Acceptance}

The most important thing in the process of policymaking in particular for the construction of nuclear installations in the country is the acceptance of the community (public acceptance) to the presence of the nuclear installation itself, especially people living in the area around the plant to be built. Making people understand the new technologies that have impacts and risks are not an easy matter, so it needs a proper and prudent manner in order to disseminate information and knowledge to the community that goes well with an open and mutual trust. Need to explain the benefits and risks that can be generated based on the facts truthfully, so that people's knowledge about nuclear plants being balanced and ultimately can judge fairly without undue influence or pressure. Dissemination of information and knowledge is not only by government alone, but also for those who really understand the conditions and the actual situation of the nuclear installation itself, including non-governmental organizations (NGOs) either agree or not agree. Communications to gain public support for nuclear plant construction program done by providing basic information and a complete and understandable to the public, especially the decisive figure subjective (opinion leaders) such as members of the people's representatives, NGOs, religious leaders and peoples and academics. Such information may include books, programs advertorials in the media, public service and or panel discussions on television and radio. The reasons either agree or disagree with the construction of a nuclear power plant could be important information and input for the government to make policies and implement programs related to the proposed construction of a nuclear installation. Public concern about the risk of accidents and the spread of radiation if built nuclear plant should also be considered. The stability of the power supply can be used as an excuse for nuclear plant construction program in order to maintain national energy security.

\section{Conclusion}

The effectiveness of the environmental impact assessment of nuclear facilities should be able to minimize the negative impacts that may arise from the establishment of a nuclear installation. Study of the impact on the physical and chemical component, biology, public health and socio-cultural activities performed on each component in order to obtain data and critical analysis of major impact. The process of determining the large and important impact at every stage of construction to postoperation need to covers the physical aspects of chemical, biological and socio-cultural. A literature review, content analysis (consulting citizens, mass media) and professional judgment need to be done in determining the method of identifying large and important impact (hypothetical). Evaluation of site characteristics affect the safety of the installation, the design of nuclear installations is evaluated based on safety standards, taking into account the characteristics of the location, the risks associated with external hazards, and the potential impact on the environment that may arise. Appropriate measures need to ensure the overall risk remains acceptable and as small as possible to increase public acceptance.

\section{References}

[1] Future Science and Technology Expected from Japan [Online] http://www.mext.go.jp/component/english/icsFiles/afieldfile/2011/ 02/23/1302525_005.pdf. [Accessed Sept. 20, 2011].

[2] Marcos, R., Carlos M. and Norberto, "A method for The assessment of The Visual Impact Caused by The Large Scale,”. Journal of Environmental Impact Assessment 30, 240-246. 2010.

[3] Ministerial Conference Beijing, "Nuclear Energy in The 21ST Century Addressing Energy Needs and Environmental Challenges," Proceeding of an International Ministerial Conference Beijing, presented at the 20-22 April 2009.

[4] Ministerial Conference Beijing, "Nuclear Energy in The $21^{\text {ST }}$ Century Addressing Energy Needs and Environmental Challenges," Proceeding of an International Ministerial Conference Beijing, presented at the 20-22 April 2009.

[5] Rashad S.M. and Hammad F.H, "Nuclear Power and The Environment: Comparatif Assessment of Environmental and Healt Impacts of Electricity Generating Systems," Journal of Applied Energy 65, 211-229. 2000.

[6] Ramana M.V. and Divya B.R., "The Environmental Impact Assessment Prosess for Nuclear Facilities: An Examination of The Indian Experience,” Journal of Environmental Impact Assessment Review (30), 268-271. 2010.

[7] Young-Il Song and John G.B. C., (2010). A New Paradigm for Environmental Assessment (EA) in Korea. Journal of Environmental Impact Assessment Review 30, 90-99. 2010. 
[8] IAEA “Site Evaluation for Nuclear Installations" Safety Standards Series No. NS-R-3 International Atomic Energy Agency. Vienna, Austria. 2003.

[9] Atomic Energy Licencing Board "Guidelines for Site Evaluation for Nuclear Power Plant,” Ministry of Science, Technology and Innovation, Selangor Darul Ehsan, LEM/TEK/64. 2011.
[10] IAEA, "External Human Induced Events in Site Evaluation for Nuclear Power Plant" Safety Guides No NS-G-3.1, International Atomic Energy Agency, Vienna, Austria. 2002.

[11] IAEA, "Defence in Depth in Nuclear Safety" INSAG-10, International Atomic Energy Agency, Vienna, Austria. 1996. 